\title{
A STUDY ON EXPECTED RISK-RETURN OF SELECTED STOCK WITH RESPECT TO GROWTH INDUSTRIES
}

\author{
Sathyanarayana K \\ Associate Professor, Surana College, P G Departments, Bangalore, India \\ Dr. R. Satheeshkumar \\ Professor, Surana College, P G Departments, Bangalore, India \\ Raghunandan N K \\ Associate Professor, Surana College, P G Departments, Bangalore, India
}

\begin{abstract}
Investors' investment activity usually revolves around high-growth industries in order to take advantage of growth in respective industry. Expected Return, Expected Risk, Co-efficient of Variation (CV) and Beta of stock have been calculated and sectorwise comparative analysis of all the above parameters have been made to analyze and present the performance of stocks of 35 companies across seven sectors. This would help investors to identify the expected return and risk associated with the stock in relation to the stock market and support investors to make appropriate investment decision. From the analysis it is found that a risk averse investor can consider investing in Godrej Properties and HDFC Bank because both these stocks have higher expected return, lower expected risk and low $C V$ and Beta value of less than 1. Next category of the stock that investor can consider investing in will be the stocks of TCS and PVR because both these stocks have higher expected return, lower CV and Beta value of less than 1. But in terms of expected risk, both of these stocks have higher expected risk.
\end{abstract}

Keywords: Beta, Expected Risk, Expected Return, Growth Industries, Stock.

Cite this Article: Sathyanarayana K, Dr. R. Satheeshkumar, Raghunandan N K, A Study on Expected Risk-Return of Selected Stock with Respect to Growth Industries, Journal of Management (JOM), 6 (3), 2019, pp. 124-133.

http://www.iaeme.com/JOM/issues.asp?JType=JOM \&VType=6\&IType=3

\section{INTRODUCTION}

Investors' investment activity usually revolves around high-growth industries to leverage the growth. Rapid growth, numerous opportunities, and quickly changing fortunes are all characteristics of industries in the growth trajectory. Investors cannot always predict the future 
direction of such industries but those who make savvy predictions stand to benefit. Investors and new companies mushroomed in the growing economic landscape were eager to raise funds through Initial Public Offerings with a strong hope of significant profits. The stock market indicators would help the investor to identify major market trends and act accordingly.

\subsection{Concepts and Terms Used Growth Industries}

Growth industries include companies across an industry exhibiting consistent growth catalysed by inflow of investments. Growth industries tend to be composed of relatively volatile and risky stocks. Often investors are willing to accept increased risk to get higher returns. Additional risks that growth industries pose can be high rate of cash burn, lack of profitability despite consumer and investor excitement, bubbles and technological setbacks that can obstruct progress.

\subsection{National Stock Exchange (NSE)}

The National Stock Exchange (NSE) is India's leading stock exchange and it was set-up to provide a modern, fully automated screen-based trading system with national reach. The Exchange has brought about unparalleled transparency, speed \& efficiency, safety and market integrity. The market today uses state-of-art information technology to provide an efficient and transparent trading, clearing and settlement mechanism, and has witnessed several innovations in products \& services viz. demutualization of stock exchange governance, screen based trading, compression of settlement cycles, dematerialization and electronic transfer of securities, securities lending and borrowing, professionalization of trading members, fine-tuned risk management systems.

\subsection{Expected Return}

The expected return on a stock is the return investors feel is most likely to occur based on currently available information.

\subsection{Risk Averse Investors}

Risk averse investors prefer lower risk with the same level of return.

\subsection{Coefficient of Variation}

Coefficient of variation indicates the variance between expected return and risk

\subsection{BETA}

A stock's beta measures its systematic risk.

\section{REVIEW OF LITERATURE AND INDUSTRY FORECASTS REPORT}

Raghavan.R.S (2000) commented on the risk perceptions and the risk measure parameters. He opined that risk measures are related to the return measurements.

Melwyn Reo (2001) reviewed the various risks to which the Indian corporates are exposed to and also the corporate risk management policies. He opined that the corporates need to focus on their primary business risks and hedge risks arising from commodity price movements.

Franco Modigliani et.al pointed out most of investors would agree that the treatment of risk is the main element in financial decision making. Key questions involve how risk should be measured, and how the required return associated with a given risk level.

Scholars have contributed much to the theories related to risk return relationship, expected value, risk and uncertainty, attitude towards risk, EVA (Economic Value Added) etc. 


\subsection{Industry Forecasts Report}

Table 1 Industry Forecasts Report

\begin{tabular}{|c|l|l|c|}
\hline SI.No & \multicolumn{1}{|c|}{ Name of the Industry } & \multicolumn{1}{c|}{ Industry Worth } & CAGR \\
\hline 1 & Indian Realty Industry & US\$ 180 billion by 2020 & $13 \%$ \\
\hline 2 & Indian automotive industry & US 251.4 billion by 2026 & $9 \%$ \\
\hline 3 & India Banking Industry & US\$ 1.31 to 1.40 trillion by $2019-20$ & $11.66 \%$ \\
\hline 4 & Indian financial services sector & US $\$ 1.47$ Trillion by 2025 & $8.55 \%$ \\
\hline 5 & India's IT \& ITeS industry & US\$350 billion by 2025 & $9 \%$ \\
\hline 6 & Indian Pharmaceutical sector & US\$ 100 billion by 2025 & $22.4 \%$ \\
\hline 7 & Indian media and entertainment & USS39.68 billion by 2025 & $13.10 \%$ \\
\hline
\end{tabular}

Source: Compiled by Author from IBEF

\subsection{Statement of the Problem}

The main problem involved in the investment decision is the lack of knowledge and awareness about the market trends and movements. This study mainly focuses on a comparative analysis of growth industries which will enable the investors to take rational investment decisions by studying the market trends and movements which can serve as a tool to predict the future behavior of the stocks.

\subsection{Objectives of the Study}

- To find out the expected return, expected risk, coefficient of variation and Beta for the selected stocks across seven sectors.

- To support the investors to take rational investment decisions through the calculated values and indicated results

\subsection{Scope of the Study}

The scope is to study the different securities of growth industries. Investors can make use of result obtained to make investments and get relative returns. This paper helps an investor to gain the necessary knowledge to judge and chose the right stock and to get the expected return and with the associated risk.

\section{RESEARCH METHODOLOGY}

Research methodology is a way to systematically solve the research problem. It may be understood as a science of studying how research is done scientifically. The various steps that are generally adopted by a researcher in studying research problem along with the logic behind them. It is necessary for the researcher to know not only the research methods/ techniques but also the methodology.

\subsection{Research Design}

Research Design was based on analytical research. Additionally, the researcher has used facts and information already available to analyze and make a critical evaluation of the data.

\subsection{Sources of Data}

Secondary Data: The sources of data used for the study is secondary data.Data required for the purpose of the study have been collected from the Websites of National Stock Exchange and Money Control website. 


\subsection{Period of the Study}

The period undertaken for the study is from 2015 to 2019 (Past four years)

\subsection{Tools Used For Analysis}

Researcher has calculated Expected Return, Risk and Coefficient of Variation for 35 leading companies across the seven sectors and comparison is made in terms of the above parameters. Beta value is also calculated to estimate the volatility of the stock.

\subsection{Limitations of the Study}

- The study is based on secondary data extracted from NSE website. The prediction accuracy is highly dependent on the accuracy of extracted data.

- Time bound research findings and suggestions have limitations on future predictions.

- The fluctuating trend of capital market and economy influence the estimation of the research.

\section{DATA ANALYSIS AND INTERPRETATION}

\subsection{Realty Sector}

Table 2 Realty Sector

\begin{tabular}{|l|c|c|c|c|c|}
\hline \multicolumn{7}{|c|}{ Date } & DLF & $\begin{array}{c}\text { OBEROIN } \\
\text { RLTY }\end{array}$ & $\begin{array}{c}\text { GODREJ } \\
\text { PROP }\end{array}$ & PHOENIX LTD & RESTIGE \\
\hline \multicolumn{7}{|c|}{ Stock Price } \\
\hline 4-May-15 & 138.30 & 289.70 & 244.25 & 362.75 & 252.05 \\
\hline 2-May-16 & 128.65 & 273.45 & 340.85 & 316.15 & 177.30 \\
\hline 2-May-17 & 189.35 & 392.75 & 506.30 & 409.30 & 240.15 \\
\hline 2-May-18 & 215.85 & 541.50 & 795.80 & 621.35 & 296.55 \\
\hline 30-Apr-19 & 172.75 & 507.30 & 829.90 & 600.20 & 261.25 \\
\hline \multicolumn{7}{|c|}{ Stock Return } & -35.18 \\
\hline 2-May-16 & -7.23 & -5.77 & 33.33 & -13.75 & 30.34 \\
\hline 2-May-17 & 8.65 & 36.21 & 39.57 & 25.82 & 21.10 \\
\hline 2-May-18 & 13.10 & 32.12 & 45.22 & 41.74 & -12.67 \\
\hline 30-Apr-19 & -22.27 & -6.52 & 4.20 & -3.46 & 0.90 \\
\hline Exp Ret & 5.56 & 14.01 & 30.58 & 12.59 & 30.33 \\
\hline Exp Risk & 26.40 & 23.33 & 18.25 & 25.67 & 33.85 \\
\hline CV & 4.75 & 1.67 & 0.60 & 2.04 & 1.05 \\
\hline Beta & 2.08 & 1.02 & 0.99 & 0.64 & \\
\hline
\end{tabular}

\section{Interpretation}

It is inferred from the analysis that Godrej Properties has the highest return of $30.58 \%$ and Prestige has the lowest return of $0.90 \%$. As per the comparison of expected risk, Godrej Properties has the least expected risk of $18.25 \%$ and Prestige has the highest risk of $30.33 \%$. As per the calculated CV, it is evident that Godrej Properties has the least variance of 0.60 and the Prestige has the highest CV of 33.85. Phoenix Ltd and Godrej Properties are low volatile investment among the reality sector in terms of Beta since it is less than 1 . 


\subsection{Auto Sector}

Table 3 Auto Sector

\begin{tabular}{|c|c|c|c|c|c|}
\hline Date & MARUTI & M\&M & BAJAJ- AUTO & $\begin{array}{c}\text { TATA } \\
\text { MOTORS }\end{array}$ & HERO MOTOCOR \\
\hline \multicolumn{7}{|c|}{ Stock Price } \\
\hline 4-May-15 & 3757.75 & 1202.50 & 2087.90 & 506.45 & 2389.55 \\
\hline 2-May-16 & 3830.85 & 1336.55 & 2477.95 & 407.70 & 2904.35 \\
\hline 2-May-17 & 6705.50 & 1340.95 & 2898.00 & 451.25 & 3352.95 \\
\hline 2-May-18 & 8744.50 & 1726.30 & 2965.95 & 336.05 & 3664.10 \\
\hline 30-Apr-19 & 6666.40 & 1290.60 & 2984.10 & 214.30 & 2511.85 \\
\hline \multicolumn{7}{|c|}{ Stock Return } \\
\hline 2-May-16 & 1.93 & 10.57 & 17.13 & -21.69 & 19.51 \\
\hline 2-May-17 & 55.98 & 0.33 & 15.66 & 10.15 & 14.36 \\
\hline 2-May-18 & 26.55 & 25.26 & 2.32 & -29.48 & 8.87 \\
\hline 30-Apr-19 & -27.13 & -29.09 & 0.61 & -44.99 & -37.76 \\
\hline Exp Ret & 14.33 & 1.77 & 8.93 & -21.50 & 1.25 \\
\hline Exp Risk & 35.39 & 22.97 & 8.67 & 23.22 & 26.36 \\
\hline CV & 2.47 & 13.00 & 0.97 & -1.08 & 21.13 \\
\hline Beta & 1.06 & 1.03 & 0.91 & 1.55 & 0.88 \\
\hline
\end{tabular}

\section{Interpretation}

It is inferred from the analysis that in the automobile sector Maruti has the highest return of $14.33 \%$ and Tata Motors has the Negative return of 21.50\%. As per the comparison of expected risk, Bajaj Auto has the least expected risk of $8.67 \%$ and Maruti has the highest expected risk of $35.39 \%$. As per the calculated CV, it is evident that Bajaj Auto has the least variance of 0.97 and the Hero Motor Corporation has the highest CV of 21.13. Bajaj Auto with the Beta Value of 0.91 stood as low volatile investment among the auto sector.

\subsection{Banking Sector}

Table 4 Banking Sector

\begin{tabular}{|c|c|c|c|c|c|}
\hline Date & HDFC BANK & $\begin{array}{c}\text { ICICI } \\
\text { BANK }\end{array}$ & $\begin{array}{c}\text { KOTAK } \\
\text { BANK }\end{array}$ & AXIS BANK & SBI \\
\hline \multicolumn{7}{|c|}{ Stock Price } \\
\hline 4-May-15 & 1000.95 & 329.30 & 1338.80 & 568.35 & 277.15 \\
\hline 2-May-16 & 1117.65 & 226.75 & 1436.40 & 471.80 & 186.00 \\
\hline 2-May-17 & 1540.60 & 275.60 & 1835.80 & 505.55 & 288.30 \\
\hline 2-May-18 & 1969.50 & 276.90 & 2513.70 & 523.75 & 241.00 \\
\hline 30-Apr-19 & 2317.45 & 407.50 & 2773.10 & 766.85 & 309.95 \\
\hline \multicolumn{7}{|c|}{ Stock Return } \\
\hline 2-May-16 & 11.03 & -37.31 & 7.04 & -18.62 & -39.88 \\
\hline 2-May-17 & 32.09 & 19.51 & 24.53 & 6.91 & 43.83 \\
\hline 2-May-18 & 24.56 & 0.47 & 31.43 & 3.54 & -17.92 \\
\hline 30-Apr-19 & 16.27 & 38.64 & 9.82 & 38.13 & 25.16 \\
\hline Exp Ret & 20.99 & 5.33 & 18.20 & 7.49 & 2.80 \\
\hline Exp Risk & 9.27 & 32.42 & 11.69 & 23.35 & 38.45 \\
\hline CV & 0.44 & 6.09 & 0.64 & 3.12 & 13.75 \\
\hline Beta & 0.77 & 1.50 & 0.97 & 1.30 & 1.49 \\
\hline
\end{tabular}




\section{Interpretation}

It is inferred from the analysis that in the banking sector, HDFC Bank has the highest return of $20.99 \%$ and SBI has the lowest return of $2.80 \%$. As per the comparison of expected risk, HDFC has the least expected risk of $9.27 \%$ and SBI has the highest expected risk of $38.45 \%$. Coefficient of variation indicates the variance between expected return and risk. As per the calculated CV, it is evident that HDFC Bank has the least variance of 0.44 and SBI has the highest CV of 13.75. HDFC Bank and Kotak Bank have the Beta Value less than 1 which is considered to be the low volatile investment among the banking sector.

\subsection{Financial Services Sector}

Table 5 Financial Services Sector

\begin{tabular}{|c|c|c|c|c|c|}
\hline Date & $\begin{array}{c}\text { BAJ } \\
\text { FINANCE }\end{array}$ & $\begin{array}{c}\text { BAJAJ } \\
\text { FINSV }\end{array}$ & I BUL HSG FIN & $\begin{array}{c}\text { BAJAJ } \\
\text { HLDNG }\end{array}$ & $\begin{array}{c}\text { SR TRANS } \\
\text { FIN }\end{array}$ \\
\hline \multicolumn{7}{|c|}{ Stock Price } \\
\hline 4-May-15 & $4,192.65$ & $1,451.10$ & 587.65 & $1,299.70$ & 828.00 \\
\hline 2-May-16 & $7,053.75$ & $1,940.90$ & 693.55 & $1,442.10$ & $1,083.00$ \\
\hline 2-May-17 & $1,268.60$ & $4,566.15$ & $1,072.55$ & $2,066.40$ & $1,008.65$ \\
\hline 2-May-18 & $1,905.10$ & $5,436.90$ & $1,298.05$ & $2,700.00$ & $1,553.20$ \\
\hline 30-Apr-19 & $3,095.95$ & $7,520.45$ & 695.45 & $3,086.00$ & $1,110.95$ \\
\hline \multicolumn{7}{|c|}{ Stock Return } \\
\hline 2-May-16 & 52.02 & 29.08 & 16.57 & 10.40 & 26.85 \\
\hline 2-May-17 & -171.56 & 85.55 & 43.60 & 35.97 & -7.11 \\
\hline 2-May-18 & 40.66 & 17.45 & 19.08 & 26.74 & 43.17 \\
\hline 30-Apr-19 & 48.56 & 32.44 & -62.41 & 13.36 & -33.51 \\
\hline Exp Ret & $\mathbf{- 7 . 5 8}$ & $\mathbf{4 1 . 1 3}$ & $\mathbf{4 . 2 1}$ & $\mathbf{2 1 . 6 2}$ & $\mathbf{7 . 3 5}$ \\
\hline Exp Risk & $\mathbf{1 0 9 . 4 3}$ & $\mathbf{3 0 . 3 0}$ & $\mathbf{4 6 . 0 5}$ & $\mathbf{1 1 . 9 2}$ & $\mathbf{3 4 . 3 6}$ \\
\hline CV & $\mathbf{- 1 4 . 4 3}$ & $\mathbf{0 . 7 4}$ & $\mathbf{1 0 . 9 4}$ & $\mathbf{0 . 5 5}$ & $\mathbf{4 . 6 8}$ \\
\hline Beta & $\mathbf{1 . 0 6}$ & $\mathbf{1 . 0 2}$ & $\mathbf{1 . 4 7}$ & $\mathbf{0 . 5 4}$ & $\mathbf{1 . 1 9}$ \\
\hline
\end{tabular}

\section{Interpretation}

It is inferred from the analysis that in the Financial Service Sector, Bajaj Financial Services has the highest return of $41.13 \%$ and Bajaj Finance has the negative return of $7.58 \%$. As per the comparison of expected risk, Bajaj Holding has the least expected risk of $11.92 \%$ and Bajaj Finance has the highest expected risk of $109.43 \%$. Coefficient of variation indicates the variance between expected return and risk. As per the calculated CV, it is evident that Bajaj Holding has the least variance of 0.55 and India Bull Housing Finance has the highest CV of 10.94. Bajaj Holding has the Beta Value of 0.54 which is less than 1 and it stood as the low volatile investment among the financial service sector.

\subsection{IT Sector}

Table 6 IT Sector

\begin{tabular}{|c|c|c|c|c|c|}
\hline Date & INFY & TCS & HCL TECH & TECH M & WIPRO \\
\hline \multicolumn{7}{|c|}{ Stock Price } \\
\hline 4-May-15 & 1993.10 & 2481.55 & 919.80 & 611.75 & 541.15 \\
\hline 2-May-16 & 1201.05 & 2526.70 & 742.20 & 477.20 & 548.50 \\
\hline 2-May-17 & 922.60 & 2289.90 & 822.05 & 418.15 & 494.90 \\
\hline 2-May-18 & 1197.05 & 3499.75 & 1000.50 & 662.55 & 275.55 \\
\hline 30-Apr-19 & 751.35 & 4520.70 & 1183.35 & 836.10 & 298.55 \\
\hline
\end{tabular}


Sathyanarayana K, Dr. R. Satheeshkumar, Raghunandan N K

\begin{tabular}{|c|c|c|c|c|c|}
\hline Date & INFY & TCS & \multicolumn{1}{c|}{ HCL TECH } & TECH M & WIPRO \\
\hline \multicolumn{7}{|c|}{ Stock Return } \\
\hline 2-May-16 & -50.65 & 1.80 & -21.45 & -24.84 & 1.35 \\
\hline 2-May-17 & -26.38 & -9.84 & 10.22 & -13.21 & -10.28 \\
\hline 2-May-18 & 26.04 & 42.42 & 19.65 & 46.03 & -58.56 \\
\hline 30-Apr-19 & -46.57 & 25.60 & 16.78 & 23.27 & 8.02 \\
\hline Exp Ret & $\mathbf{- 2 4 . 3 9}$ & $\mathbf{1 4 . 9 9}$ & $\mathbf{6 . 3 0}$ & $\mathbf{7 . 8 1}$ & $\mathbf{- 1 4 . 8 7}$ \\
\hline Exp Risk & $\mathbf{3 5 . 2 6}$ & $\mathbf{2 3 . 4 9}$ & $\mathbf{1 8 . 9 2}$ & $\mathbf{3 2 . 7 0}$ & $\mathbf{3 0 . 0 9}$ \\
\hline CV & $\mathbf{- 1 . 4 5}$ & $\mathbf{1 . 5 7}$ & $\mathbf{3 . 0 0}$ & $\mathbf{4 . 1 9}$ & $\mathbf{- 2 . 0 2}$ \\
\hline Beta & $\mathbf{0 . 6 7}$ & $\mathbf{0 . 5 4}$ & $\mathbf{0 . 6 3}$ & $\mathbf{0 . 7 2}$ & $\mathbf{0 . 5 1}$ \\
\hline
\end{tabular}

\section{Interpretation}

It is inferred from the analysis that in the IT Sector, TCS has the highest return of $14.99 \%$ and Infosys has the negative return of $24.39 \%$. As per the comparison of expected risk, HCL Technology has the least expected risk of $18.92 \%$ and Infosys has the highest expected risk of $35.26 \%$. Coefficient of variation indicates the variance between expected return and risk. As per the calculated CV, it is evident that TCS Stock has the least variance of 1.57 and Tech Mahindra has the highest CV of 4.19. It is evident from the calculated Beta Value, all firm namely Infosys, TCS, HCL Technology, Tech Mahindra and Wipro have Beta Value of less than 1 and it is clear that all the firms' stock are considered to be the low volatile investment.

\subsection{Media Sector}

Table 7 Media Sector

\begin{tabular}{|c|c|c|c|c|c|}
\hline Date & ZEEL & PVR & SUNTV & DISH TV & TV18 BRD CST \\
\hline \multicolumn{7}{|c|}{ Stock Price } \\
\hline 4-May-15 & 320.95 & 631.75 & 369.40 & 76.50 & 34.00 \\
\hline 2-May-16 & 416.40 & 826.45 & 369.65 & 90.45 & 38.45 \\
\hline 2-May-17 & 534.20 & 1600.60 & 923.95 & 95.15 & 41.60 \\
\hline 2-May-18 & 596.30 & 1408.55 & 871.80 & 74.85 & 61.90 \\
\hline 30-Apr-19 & 432.60 & 1769.45 & 574.25 & 36.00 & 31.30 \\
\hline \multicolumn{7}{|c|}{ Stock Return } \\
\hline 2-May-16 & 26.04 & 26.86 & 0.07 & 16.75 & 12.30 \\
\hline 2-May-17 & 24.91 & 66.10 & 91.61 & 5.07 & 7.87 \\
\hline 2-May-18 & 11.00 & -12.78 & -5.81 & -24.00 & 39.74 \\
\hline 30-Apr-19 & -32.09 & 22.81 & -41.75 & -73.20 & -68.19 \\
\hline Exp Ret & $\mathbf{7 . 4 6}$ & $\mathbf{2 5 . 7 5}$ & $\mathbf{1 1 . 0 3}$ & $\mathbf{- 1 8 . 8 4}$ & $\mathbf{- 2 . 0 7}$ \\
\hline Exp Risk & $\mathbf{2 7 . 2 4}$ & $\mathbf{3 2 . 2 6}$ & $\mathbf{5 6 . 8 1}$ & $\mathbf{4 0 . 0 8}$ & $\mathbf{4 6 . 2 8}$ \\
\hline CV & $\mathbf{3 . 6 5}$ & $\mathbf{1 . 2 5}$ & $\mathbf{5 . 1 5}$ & $\mathbf{- 2 . 1 3}$ & $\mathbf{- 2 2 . 3 7}$ \\
\hline Beta & $\mathbf{0 . 9 8}$ & $\mathbf{0 . 8 5}$ & $\mathbf{1 . 3 2}$ & $\mathbf{1 . 3 0}$ & $\mathbf{1 . 5 3}$ \\
\hline
\end{tabular}

\section{Interpretation}

It is inferred from the analysis that in the Financial Service Sector, PVR has the highest return of $25.75 \%$ and Dish TV has the negative return of $18.84 \%$. As per the comparison of expected risk, ZEEL has the least expected risk of $27.24 \%$ and SUN TV has the highest expected risk of $56.81 \%$. Coefficient of variation indicates the variance between expected return and risk. As per the calculated CV, it is evident that PVR Stock has the least variance of 1.25 and SUN TV has the highest CV of 5.15. PVR and ZEEL has the Beta Value of 0.85 and 0.98 respectively which is less than 1 and it is considered to be the low volatile investment among the media sector. 
A Study on Expected Risk-Return of Selected Stock with Respect to Growth Industries

\subsection{Pharma Sector}

Table 8 Pharma Sector

\begin{tabular}{|c|c|c|c|c|c|}
\hline Date & SUN PHARMA & DR REDDY & CIPLA & AURO PHARMA & DIVIS LAB \\
\hline \multicolumn{7}{|c|}{ Stock Price } \\
\hline 4-May-15 & 947.75 & 3395.05 & 673.70 & 1304.30 & 1783.45 \\
\hline 2-May-16 & 811.80 & 3011.80 & 540.65 & 1539.70 & 1055.80 \\
\hline 2-May-17 & 632.80 & 2582.65 & 555.35 & 1193.60 & 1253.50 \\
\hline 2-May-18 & 515.20 & 2118.20 & 612.00 & 1266.50 & 2377.60 \\
\hline 30-Apr-19 & 457.65 & 2933.75 & 565.00 & 1638.10 & 3493.70 \\
\hline \multicolumn{7}{|c|}{ Stock Return } \\
\hline 2-May-16 & -15.48 & -11.98 & -22.00 & 16.59 & -52.43 \\
\hline 2-May-17 & -24.91 & -15.37 & 2.68 & -25.46 & 17.16 \\
\hline 2-May-18 & -20.56 & -19.82 & 9.71 & 5.93 & 64.02 \\
\hline 30-Apr-19 & -11.85 & 32.57 & -7.99 & 25.73 & 38.49 \\
\hline Exp Ret & $\mathbf{- 1 8 . 2 0}$ & $\mathbf{- 3 . 6 5}$ & $\mathbf{- 4 . 4 0}$ & $\mathbf{5 . 7 0}$ & $\mathbf{1 6 . 8 1}$ \\
\hline Exp Risk & $\mathbf{5 . 7 3}$ & $\mathbf{2 4 . 3 6}$ & $\mathbf{1 3 . 8 1}$ & $\mathbf{2 2 . 2 9}$ & $\mathbf{4 9 . 9 7}$ \\
\hline CV & $\mathbf{- 0 . 3 1}$ & $\mathbf{- 6 . 6 7}$ & $\mathbf{- 3 . 1 4}$ & $\mathbf{3 . 9 1}$ & $\mathbf{2 . 9 7}$ \\
\hline Beta & $\mathbf{0 . 8 3}$ & $\mathbf{0 . 6 1}$ & $\mathbf{0 . 7 9}$ & $\mathbf{1 . 2 1}$ & $\mathbf{0 . 8 3}$ \\
\hline
\end{tabular}

\section{Interpretation}

It is inferred from the analysis that in the Pharma Sector, Divis Lab has the highest return of $16.81 \%$ and Sun Pharma has the negative return of $18.20 \%$. As per the comparison of expected risk, Sun Pharma has the least expected risk of 5.73\% and Divis Lab has the highest expected risk of $49.97 \%$. Coefficient of variation indicates the variance between expected return and risk. As per the calculated CV, it is evident that Divis Lab has the least variance of 2.97 and India Bull has the highest CV of 3.91. It is evident from the calculated Beta Value, all firms except Auro Pharma has Beta Value of less than 1 and it is clear that all the firms' stock except Auro Pharma are considered to be the low volatile investment.

\section{FINDINGS OF THE STUDY}

Findings of the study is listed out based on Expected Return, Expected Risk, Coefficient of Variation and Beta Value analysis.

\subsection{Expected Return}

- It is clear that Godrej has the highest return of $30.58 \%$ amongst five reality firms.

- It is inferred from the analysis that in the automobile sector, Maruti has the highest return of $14.33 \%$.

- It is inferred from the analysis that HDFC Bank has the highest return of $20.99 \%$ among the banking sector.

- It is evident that among the Financial Service Sector, Bajaj Fin Service has the highest return of $41.13 \%$.

- It is found from the analysis that among the IT Sector, TCS has the highest return of $14.99 \%$.

- It is inferred from the analysis that in the Media sector, PVR has the highest return of $25.75 \%$.

- It is found that Divis Lab has the highest return of $16.81 \%$ among the Pharma Sector.

\subsection{Expected Risk}

- Godrej Properties has the least expected risk of $18.25 \%$ as per the comparison of expected risk among five reality firms. 
- As per the comparison of expected risk among auto sector, Bajaj Auto has the least expected risk of $8.67 \%$.

- HDFC Bank has the least expected risk of $9.27 \%$ among the banking sector in terms of expected risk.

- It is evident that among the Financial Service Sector, Bajaj Holding has the least expected risk of $11.92 \%$.

- As per the comparison of expected risk, HCL Technology has the least expected risk of $18.92 \%$.

- ZEEL has the least expected risk of $27.24 \%$ among the media sector in terms of expected risk.

- It is clear from the expected risk comparison among the Pharma sector, Sun Pharma has the least expected risk of $5.73 \%$.

\subsection{Coefficient of Variation}

- It is evident that Godrej Properties has the least variance of 0.605 as per the calculated CV among the reality firms.

- Bajaj Auto Stock has the least variance of 0.97 in terms of CV among the Auto sector.

- HDFC Bank has the least variance of 0.44 among the banking sector.

- It is evident that Bajaj Fin Service has the least variance of 0.74 as per the calculated CV among the Financial Services Sector.

- As per the calculated CV, it is evident that TCS has the least variance of 1.57 among the IT Sector.

- PVR Stock has the least variance of 1.25 among the five firms in Media sector.

- As per the calculated CV, it is evident that Divis Lab has the least variance of 2.97.

\subsection{BETA}

- Phoenix Ltd and Godrej Properties are low volatile investment among the reality sector in terms of Beta since it is less than 1 .

- Bajaj Auto Stock with the Beta Value of 0.91 stood as low volatile investment among the auto sector.

- HDFC Bank and Kotak Bank has the Beta Value less than 1 which is considered to be the low volatile investment among the banking sector.

- Bajaj Holding has the Beta Value of 0.54 which is less than 1 and it stood as the low volatile investment among the financial service sector.

- All firm namely Infosys, TCS, HCL Technology, Tech Mahindra and Wipro has Beta Value of less than 1 and it is clear that all the firms' stock are considered to be the low volatile investment amongst IT Sector.

- PVR and ZEEL has the Beta Value of 0.85 and 0.98 respectively which is less than 1 and it is considered to be the low volatile investment among the media sector.

- All firms except Auro Pharma has Beta Value of less than 1 and it is clear that all the firms' stock except Auro Pharma are considered to be the low volatile investment.

\section{SUGGESTIONS}

Based on the analysis and findings of the study, it is suggested that a risk averse investor can consider investing in the stocks of Godrej Properties in the reality sector, HDFC Bank in the 
banking sector because both stocks have higher expected return, lower expected risk and low $\mathrm{CV}$ and Beta value of less than 1.

Next category of the stock that an investor can consider investing in should be the stocks of TCS in the IT sector, PVR in the Media sector. Both have higher expected return, and low CV and Beta value of less than 1. But in terms of expected risk, these stocks have higher expected risk. It is suggested that investors with an ability to bear higher risk can invest in these stocks and can expect higher returns on their investment.

\section{CONCLUSION}

This study mainly focuses on expected return and risk associated with a stock and it is concluded from the analysis of Expected Return, Expected Risk, Co-efficient of Variation and Beta of stock that a risk averse investor can consider investing in the stocks of Godrej Properties, HDFC Bank since these stocks have higher expected return with lower expected risk, low CV and Beta value of less than 1. An investor with an appetite for higher risk can consider investing in the stocks of TCS and PVR because these stocks have higher expected return with lower $\mathrm{CV}$ and Beta value of less than 1. But in terms of expected risk, both of these have higher expected risk.

\section{REFERENCES}

[1] Punithavathy Pandian, Security Analysis and Portfolio Management, Vikas Publishing House Private Limited, Fifth Reprint Edition, 2005

[2] Keith Brown, Frank Reilly, Investment Analysis \& Portfolio Management, Cengage Learning Publishing, 10th Edition, 2012

[3] Raghavan.R.S., "Risk Management in Banks", TIre Hiildtr, Daily, Vol. 123, No. 272, November,2000,Business,p.4.

[4] https://www.nseindia.com/products/content/equities/equities/eq_security.htm

[5] http://www.utdallas.edu/ herve/abdi-cv2010-pretty.pdf

[6] https://dspace.mit.edu/bitstream/handle/1721.1/1863/SWP-0646-14474903.pdf by Franco Modigliani and Gerald A, an Introduction to Risk and Return Concepts and Evidence.

[7] http://www.swlearning.com/ibc/lasher4e/pdf/66798_c08_306-354.pdf

[8] https://shodhganga.inflibnet.ac.in/bitstream/10603/274/9/09_chapter\%203.pdf

[9] https://www.marketwatch.com/press-release/new-research-study-on-security-riskanalysis-software-market-predicts-steady-growth-till-2024-2019-05-03

[10] https://www.techsciresearch.com/report/india-banking-market/3209.html

[11] https://www.ibef.org/industry/information-technology-india.aspx

[12] https://www.ibef.org/industry/pharmaceutical-india.aspx 